Société d'histoire de la révolution de 1848 et des

révolutions du XIXe siècle

$37 \mid 2008$

L'ère victorienne revisitée

\title{
Charles DIDIER, Rome souterraine, édition critique par Sophie Guermès
}

Jean-Noël Tardy

\section{OpenEdition}

Journals

Édition électronique

URL : http://journals.openedition.org/rh19/3529

DOl : $10.4000 /$ rh 19.3529

ISSN : $1777-5329$

Éditeur

La Société de 1848

Édition imprimée

Date de publication : 15 novembre 2008

Pagination : 185-242

ISSN : 1265-1354

Référence électronique

Jean-Noël Tardy, "Charles DIDIER, Rome souterraine, édition critique par Sophie Guermès », Revue d'histoire du XIXe siècle [En ligne], 37 | 2008, mis en ligne le 01 décembre 2008, consulté le 22 septembre 2020. URL : http://journals.openedition.org/rh19/3529 ; DOI : https://doi.org/10.4000/ rh19.3529

Ce document a été généré automatiquement le 22 septembre 2020

Tous droits réservés 


\title{
Charles DIDIER, Rome souterraine, édition critique par Sophie Guermès
}

\author{
Jean-Noël Tardy
}

\section{RÉFÉRENCE}

Charles DIDIER, Rome souterraine, édition critique par Sophie Guermès, « Textes littéraires français » (593), Genève, Droz, 2007, 733 p. ISBN : 978-2-600-00696-5. 64,06 euros.

1 Saluons la réédition d'un roman depuis longtemps introuvable, Rome souterraine, du Suisse Charles Didier. En 1833, l'ouvrage, aujourd'hui bien oublié, ne passa pas inaperçu : il obtint les éloges des partisans des causes nationales, nombreux au début de la monarchie de Juillet; et, en 1835, la première place des ouvrages français condamnés par la Congrégation de l'Index. L'auteur, Charles Didier, est quant à lui davantage connu pour sa liaison avec George Sand que pour son œuvre littéraire, au demeurant peu abondante: Rome souterraine se distingue comme son seul véritable succès.

C'est le roman d'une conspiration: cette Rome souterraine, c'est celle des sociétés secrètes, des carbonari qui ont réinvesti les catacombes des premiers chrétiens. Ces conspirateurs souhaitent mettre à profit le temps du conclave pour provoquer une révolution à Rome et créer la république ausonienne, le régime politique utopique qui réalisera l'unité italienne. Héroïsme, fermeté, intelligence caractérisent leurs actes et ces vertus s'incarnent au plus haut point dans la figure héroïque du grand maître des carbonari de Rome, Anselme. Cependant l'unité italienne est aussi le but poursuivi par une autre société secrète : l'aristocratique société des sanfédistes. Celle-ci aspire à une Italie des princes fédérés sous l'autorité d'un pape acquis à leur cause. L'homme qui porte leurs espoirs au conclave est le Grand Pénitencier, le cardinal de Pétralie. Mais cet être exceptionnel, parti de rien, ce «bâtard de Sicile », n'est pas le simple pion des conservateurs. Il veut redonner à la papauté sa puissance passée et à l'Italie son unité. 
Anselme, infiltré au sein des sanfédistes pour connaître leurs projets, se lie au cardinal qui lui confesse son secret. Les deux hommes font alliance. Mais la police secrète autrichienne met successivement en échec les projets du Grand Pénitencier puis l'insurrection des carbonari, provoquant son lot de nouveaux martyrs.

L'intérêt du roman pour l'historien n'est pas immédiatement évident. L'ouvrage n'est pas un témoignage, même romancé, d'événements historiques précis. Il se démarque ainsi des romans historiques à la Walter Scott. Les noms des papes et des souverains ne sont pas précisés. Les personnages à l'œuvre sont fictifs. Certes, certains épisodes sont inspirés de l'histoire récente. Comme le souligne Sophie Guermès dans son introduction, l'échec du cardinal de Pétralie au conclave rappelle celui du cardinal Severoli en 1823 à la mort de Pie VII. Signalons ici la qualité de l'introduction et de l'appareil critique, en particulier sur la vie de la Curie, citant de manière judicieuse deux témoins précieux de l'Italie de la Restauration, Stendhal et Chateaubriand. La Charbonnerie italienne ne bénéficie pas toutefois du même éclairage critique. L'organisation, il est vrai, demeure obscure. On regrettera malgré tout l'absence dans la bibliographie de l'ouvrage de Bourg Saint-Edme sur les rites de la société ${ }^{1}$, assurément connu de Charles Didier, et celle de synthèses récentes, comme le volume 21 de la Storia d'Italia dirigé par Gian Mario Cazzaniga, ou, en français, l'ouvrage La Charbonnerie française de Pierre-Arnaud Lambert qui consacre un bon chapitre à sa consœur italienne ${ }^{2}$. Cela aurait permis de préciser davantage les sources de Charles Didier. Comme le conclave, l'insurrection ratée s'inspire d'un précédent de 1817: la conspiration, à Macerata dans les États de l'Église, de carbonari qui souhaitaient profiter de la maladie de Pie VII, que la rumeur annonçait comme fatale. Néanmoins, comme le constate Sophie Guermès, les développements du romancier sur la Charbonnerie sont largement mythiques et si l'intrigue de Rome souterraine emprunte à des exemples passés, elle s'en affranchit et refuse toute chronologie définie. De même, sur la clandestinité ou les techniques policières, le roman apprend peu de choses. Les personnages tiennent pour beaucoup de l'allégorie: la police secrète est incarnée principalement par un personnage, l'indicateur italien au service de l'Autriche, véritable Protée policier, omniprésent dans l'ouvrage.

4 Cette dimension documentaire écartée, le roman perd-t-il tout intérêt pour l'historien? Nous ne le pensons pas. Il participe de la construction d'un imaginaire, républicain et révolutionnaire. Il s'intègre dans un vaste mouvement politique et intellectuel autour de George Sand, Pierre Leroux ou Michel de Bourges. L'imprécision chronologique de l'intrigue est en elle-même un élément signifiant. L'ouvrage développe une vision de l'Histoire comme produit de luttes occultes, partagée par bien des écrivains romantiques, George Sand ${ }^{3}$ ou Thomas de Quincey, fascinés par les sociétés secrètes et " leur défi à la mortalité, semblable à celui du phénix " ${ }^{4}$. De fait, Charles Didier attribue à la Charbonnerie la mission sacrée d'affranchir les peuples et une capacité formidable à traverser les siècles. Le personnage survivant emporte cette mémoire qui fera naître de nouveaux apôtres jusqu'à la victoire finale, prophétisée par Napoléon, cet autre mythe romantique, en exergue de l'ouvrage. En outre, on remarque avec les références classiques à la Rome républicaine, celle de Machiavel et de la Révolution française, la justification étonnante et subversive de la violence politique, regrettée mais excusée au nom de l'oppression de l'Italie. C'est que la politique est impérieuse, conçue comme une religion qui exige que tout lui soit sacrifié : les arts, la vie et l'amour. De fait, les relations amoureuses, souvent considérées comme des concurrentes du devoir, frappent par leur absence d'originalité. La maladresse de Charles Didier dans ce 
domaine a fréquemment été soulignée. Mais cela ne signifie pas que l'historien ne puisse pas faire son miel de ces intrigues stéréotypées et, de manière plus globale, des catégorisations de genre qui émaillent la prose de l'auteur. Ainsi dans son univers, la ténacité, le sens du sacrifice, l'intelligence politique sont des qualités viriles. À l'inverse, le carbonaro qui compromet ses pairs par sa liaison avec une aristocrate se retrouve stigmatisé comme efféminé. Seule la femme aimée par le héros, en lutte avec un père, officier lâche et cruel, échappe à cette dévalorisation pour devenir une allégorie de l'Italie prisonnière.

5 Ces multiples lectures possibles du roman nous font donc espérer que cette belle réédition de Rome souterraine trouvera sa place dans les bibliothèques des historiens mais aussi, plus largement, parmi celles des amateurs de romans historiques et des amoureux de l'Italie.

\section{NOTES}

1. . E.-T. Bourg Saint-Edme, Constitution et organisation des Carbonari, Paris, Corby, 1821.

2. . Gian Mario Cazzaniga, Storia d'Italia. Annali 21. La Massoneria, Turin, G. Einaudi, 2006 ; PierreArnaud Lambert, La Charbonnerie française. 1921-1923. Du secret en politique, Lyon, Presses Universitaires de Lyon, 1995 ( $22^{\mathrm{e}}$ édition).

3. . Voir George Sand, La Comtesse de Rudolstadt, publié dans La Revue indépendante, du 25 mai 1843 au 10 février 1844. Pour une réédition récente : Consuelo, 2. La comtesse de Rudolstadt, «Libretto ", Paris, Phébus, 1999.

4. . Thomas de Quincey, Les sociétés secrètes, Paris, Le Promeneur, 1994 (1 ${ }^{\text {re }}$ édition 1847), p. 28-29. 